\title{
Frequency of cardiovascular risk factors in adult Nigerians with family history of non-communicable cardiovascular disease in a primary care clinic of a tertiary hospital in a resource-constrained environment of eastern Nigeria
}

\author{
Gabriel Uche Pascal Iloh ${ }^{1, *}$, Abali Chuku², Nnadozie Paul Obiegbu ${ }^{3}$, John Nnaemeka Ofoedu ${ }^{1}$, \\ Augustin Obiora Ikwudinma ${ }^{4}$ \\ ${ }^{1}$ Department of Family Medicine, Federal Medical Centre, Umuahia, Abia state, Nigeria \\ ${ }^{2}$ Department of Ophthalmology Federal Medical Centre, Umuahia, Abia state, Nigeria \\ ${ }^{3}$ Ministry of Health, Awka, Anambra State, Nigeria and Trainer in Family Medicine Residency program, Department of Family Medicine, \\ Federal Medical Centre, Umuahia, Nigeria \\ ${ }^{4}$ Department of Family Medicine, Federal Teaching Hospital Abakiliki, Nigeria
}

Email address:

ilohgup2009@yahoo.com (G. U. P. Iloh)

\section{To cite this article:}

Gabriel Uche Pascal Iloh, Abali Chuku, Nnadozie Paul Obiegbu, John Nnaemeka Ofoedu, Augustin Obiora Ikwudinma. Frequency of Cardiovascular Risk Factors in Adult Nigerians with Family History of Non-Communicable Cardiovascular Disease in a Primary Care Clinic of a Tertiary Hospital in a Resource-Constrained Environment of Eastern Nigeria. American Journal of Health Research.

Vol. 1, No. 1, 2013, pp. 17-25. doi: 10.11648/j.ajhr.20130101.13

\begin{abstract}
Background: Cardiovascular (CV) risk factors tend to cluster in persons with family history of cardiovascular diseases (CVDs) with variable distribution and penetrance. Screening adult Nigerians with immutable family history of CVD for other conventional CV risk factors is an important primary care challenge that is often neglected especially in resource-constrained settings. Aim: This study was designed to determine the frequency of cardiovascular risk factors in adult Nigerians with family history of non-communicable cardiovascular disease in a primary care clinic of a tertiary hospital in a resource-constrained environment of Eastern Nigeria. Materials and Methods: A descriptive facility-based study carried out on 440 consecutive adult Nigerians with family history of at least one of the major non-communicable CVDs in Nigeria who were screened for CV risk factors. Basic demographic variables, cardio-metabolic and behavioural risk factors were obtained using a pretested, structured and researcher-administered questionnaire. The conventional CV risk factors studied were hypertension, obesity, diabetes mellitus, physical activity, alcohol and tobacco use. Family history of CVD refers to previous information on any major CVDs such as hypertension, heart failure, myocardial infarction and stroke in any of the first, second and third degree generation family members who were dead or alive made by a health professional. Results: The three most frequent cardiovascular risk factors were physical inactivity (81.6\%), asymptomatic hypertension (26.4\%) and obesity (18.9\%). Others included alcohol use (17.5\%), diabetes mellitus (7.7\%) and tobacco use (5.7\%). Conclusion: This study has shown that CV risk factors exist among the study population with three most common being physical inactivity, asymptomatic hypertension and obesity. Screening adult Nigerians with family history of CVD for cardio-metabolic and behavioural CV risk factors should form baseline evaluation for these patients during clinical encounter in primary care.
\end{abstract}

Keywords: Adult Nigerians, Family History of CVD, Primary Care, CV Risk Factors

\section{Introduction}

Cardiovascular disease (CVD) is a global health problem presently escalating in developing countries as an important component of non-communicable disease burden. [1-3] Globally, before 1900, cardiovascular disease accounts for less than $10 \%$ of all deaths.[4] Today, however, cardiovascular disease is responsible for about $30 \%$ of 
deaths worldwide, including nearly $40 \%$ in high-income nations and about $28 \%$ in low- and middle-income countries.[4,5] In 1990, cardiovascular disease was responsible for $28 \%$ of the world's 50.4 million deaths and $9.7 \%$ of the 1.4 billion lost disability-adjusted life years (DALYs).[4] In 2001, cardiovascular disease accounted for $29 \%$ of all deaths and $14 \%$ of the 1.5 billion lost disabilityadjusted life years and by 2030, when the population is expected to reach 8.2 billion, $32.5 \%$ of all deaths will be the result of cardiovascular disease.[4,5]

In the last decade in Nigeria [6,7] and other parts of the world such as India [8] and Saudi Arabia [9], cardiovascular diseases have become a major clinic and public health problem. It is characterized by high rates of disability, case fatality and unnecessary deaths particularly in Nigeria.[7,10] However, there is a myth in Nigeria that death whether sudden or protracted from myocardial infarction(heart attack) or stroke(brain attack) is frequently attributed to spells on the family.[6,10] The national survey in Nigeria [11] and recent research reports in Nigeria $[3,6,7,12,13]$ showed that the prevalence of cardiovascular diseases is increasing in all parts of Nigeria. Similar increases in cardiovascular diseases have been reported in other parts of the world such as Cameroon [14] and India.[8]

Research have shown that variability of cardiovascular diseases across the world is a factor of genetic(family history), metabolic and socio-environmental factors.[2,3,15] Major non-communicable cardiovascular diseases that have been documented to share similar conventional modifiable and non-modifiable risk factors and their frequency distribution reportedly varies within and across different populations of the world.[15-17] Apart from the metabolic risk factors of cardiovascular diseases such as hypertension, obesity, diabetes mellitus and dyslipidaemia,[6] behavioural risk factors like smoking, excessive alcohol consumption and physical inactivity, and non-modifiable family history of cardiovascular risk factor have also been implicated in the occurrence of cardiovascular diseases among the world population.[16-19]

The relevance of family history as the most important tool for diagnosis in medical genetics have been reported as a critical element in risk assessment for many genetic conditions in primary care settings.[20] Studies on the cardiovascular risk factors among patients with family history of cardiovascular diseases in primary care settings in Nigeria are not available. Research studies in the Nigerian sub-region on cardiovascular risk factors did not focus on persons with non-modifiable family history of CVDs but on hypertensive patients in hospitals, [12,13] general Nigerian population[17] and other population group such as priests, [21] company executives[22] and other groups. The early recognition of the irrevocable risk factor of family history of cardiovascular disease that predispose to these cardiovascular diseases is essential to the management of individual patients in primary care settings and also in the prevention of the disease in the family and community through provision of patient-centred, person- centred, family-centred and community-centred longitudinal and continuity of care. [23] Identifying positive family history of cardiovascular disease visa-viz, other cardiovascular risk factors particularly those of patho-physiologic (cardio-metabolic) nature and behavioural (lifestyle-related) factors which are amenable to effective interventions [24-26] therefore avails great opportunity for early health promotion and risk reduction on lifestyle modification as well as screening for cardiometabolic risk factors especially in resource-poor settings where health care seeking behaviour and utilization are largely driven by the need for curative services rather than imperative for preventive and promotive care services. The present study was therefore undertaken to provide data on the frequency of cardiovascular risk factors in adult Nigerians with family history of non-communicable cardiovascular disease in a primary care clinic of a tertiary hospital in resource-poor environment of Eastern Nigeria.

\section{Materials and Methods}

\subsection{Ethical Consideration}

Ethical certificate was obtained from the Health Research and Ethics Committee of the hospital. Informed consent was also obtained from patients included in the study.

\subsection{Study Design}

This was a primary care clinic-based descriptive study carried out on 440 adult Nigerian patients with family history of cardiovascular disease from February 2012 to May 2012 at the department of Family Medicine of Federal Medical Centre, Umuahia, a tertiary hospital in Umuahia, Abia state, South-Eastern, Nigeria.

\subsection{Study Setting}

Umuahia is the capital of Abia state, South-East Nigeria. The State is endowed with abundant mineral and agricultural resources with supply of professional, skilled, semi-skilled and unskilled manpower. Economic and social activities are low compared to industrial and commercial cities such as Onitsha, Port Harcourt and Lagos in Nigeria. Until recently, the capital city and its environ have witnessed an upsurge in the number of banks, hotels, schools, markets, industries, junk food restaurants in addition to the changing dietary and social lifestyles.

Federal Medical Centre, Umuahia is located in the metropolitan city of Umuahia. It is a tertiary hospital established with the tripartite mandate of service delivery, training and research and serves as a referral Centre for primary and secondary public health institutions as well as missionary and private hospitals in Abia state and neighbouring states of Imo, Ebonyi, Rivers and Akwa Ibom states of Nigeria.

The department of Family Medicine serves as a primary care clinic within the tertiary hospital setting of the Federal 
Medical Centre. All adult patients excluding those who need emergency health care services, paediatric patients and antenatal women are first seen at the department of Family Medicine where diagnoses are made. Patients who need primary care are managed and followed up in the clinic while those who need other specialists care are referred to the respective core specialist clinics for further management. The clinic is run by Consultant Family Physicians and postgraduate resident doctors in Family Medicine.

\subsection{Study Population}

The study population was made up of 440 adult Nigerian patients with family history of cardiovascular disease who met the inclusion criteria.

\subsection{Inclusion and Exclusion Criteria}

The inclusion criteria were Nigerian patients with family history of any of the cardiovascular disease aged $\geq 18$ years and who gave informed consent for the study. The exclusion criteria included Nigerian patients who in addition to family history of CVD had also personal history of health professional diagnosed cardiovascular diseases such as hypertension, heart failure, coronary artery diseases and cerebrovascular accident. More so, pregnant patients, patients who had ascites and other forms of oedema and physical deformities determined by history and physical examination affecting the spine and/or the limbs who could not stand for height and weight anthropometric measurements and critically ill patients were excluded.

\subsection{Sample Size Determination}

Sample size estimation was determined using the formula [27] for calculating minimum sample size for descriptive studies $\mathrm{N}=\mathrm{Z}^{2} \mathrm{pq} / \mathrm{d}^{2}$ where $\mathrm{N}=$ Minimum sample size, $Z=$ Standard normal deviation usually set at 1.96 which corresponds to $95 \%$ confidence interval, $\mathrm{P}=$ Proportion of the population estimated to have a particular characteristic. Due to the absence of similar study on specific population of patients with family history of CVD and the multivariate nature of the $\mathrm{CV}$ risk factors, thus there was no reasonable estimate for the prevalence of combined CV risk factors; the researchers therefore assumed that $50 \%$ of the patients would have at least one of the CV risk factors at $95 \%$ confidence level and 5\% margin of error. This gave a sample size estimate of 384 ; thus $\mathrm{q}=1.0-\mathrm{p}=1.0-0.5=0.5$, $\mathrm{d}=$ degree of accuracy set at 0.05 . Hence $\mathrm{N}=(1.96)^{2} \mathrm{x}$ $0.5 \times 0.5 /(0.05)^{2}$. Therefore, $\mathrm{N}=384$. The calculated minimum sample size was 384 . However, to improve the precision of the study and compensate for non-response, the estimated sample size $=\mathrm{Ns}$ was determined considering an anticipated response rate of $90 \%(0.9)$. The estimated sample size (Ns) was determined by dividing the original calculated sample size $(\mathrm{N})$ by the anticipated response rate [27] as follows, $\mathrm{Ns}=\mathrm{N} / 0.9$, where $\mathrm{N}=$ Minimum calculated sample size, $\mathrm{Ns}=$ Selected sample size, anticipated response rate $=0.9$. Thus, the estimated sample size $=384 / 0.9=426$. However, a sample size of 440 patients was used based the duration of the study.

\subsection{Sampling Technique}

The sample selection was done consecutively using every adult patient who registered to see the clinicians on each consulting day during the study period and who met the inclusion criteria. This sampling technique was judgmentally chosen by the authors based on the fact that the researchers believed that those selected were likely to be representative of the study population.

\subsection{Diagnostic Procedures for Cardio-Metabolic Risk Factors}

Cardio-metabolic risk factors were evaluated by anthropometric measurements of weight and height and estimation of body mass index, clinical assessment of blood pressure and laboratory determination of fasting plasma glucose.

The weight was measured in kilograms with patients standing bare feet in their minimal clothing and with their pockets free of objects that might add to their weights such as mobile phones, wallets, keys, rings etc using prevalidated stadiometer combined with weighing scale. The zero mark of the weighing scale was checked every morning before use and after each measurement. In measuring the height, the patient who was barefooted and without head-gear or cap stood against the stadiometer on the weighing scale with the Achilles, gluteus and occiput touching it. A pointer was pressed firmly against the scalp and the measurement read off on the scale in meters to the nearest $0.5 \mathrm{~cm}$. The body mass index was estimated by dividing measured weight in kilograms by the height in meters squared.

The blood pressure was measured using auscultatory method with standard mercury in glass Accuson sphygmomanometer.[6] Prior to the measurement, the patient was seated and rested for 5 minutes[28] in sitting position on a chair that supported the back comfortably. The left arm muscles were relaxed and the forearm was supported with the cubital fossa at the heart level. A cuff of suitable size was applied evenly to the exposed arm. The cuff was rapidly inflated until the manometer reading was about $30 \mathrm{mmHg}$ above the level at which the pulse disappeared and then slowly deflected. During this time, the Korotkoff sounds were monitored using a Litman stethoscope placed over the brachial artery. The systolic blood pressure was noted at the pressure at which the first heart sounds were heard(Korotkoff phase I). The diastolic blood pressure was taken as the pressure at the point when the heart sounds disappeared(Korotkoff phase v). The blood pressure was also measured in the right arm as described for the left arm in order to rule out significant inter-arm blood pressure difference and the arm that gave the higher reading was subsequently used. [28] 
The blood glucose was determined after an overnight fast between 8.00 hours to 10.00 hours using venous plasma by glucose oxidase method.[6] A repeat fasting plasma glucose was done for those who had abnormal fasting plasma glucose test result on the next scheduled clinic visit.

\subsection{Diagnostic Criteria for Cardio-Metabolic Risk Factors}

The body mass index of $\geq 30 \mathrm{~kg} / \mathrm{m}^{2}$ was taken as the definition of obesity.[6] Hypertension was defined as the systolic and/or diastolic blood pressures of $\geq 140 / 90 \mathrm{mmHg}$ or documented use of antihypertensive medications in a previously diagnosed person with hypertension. [6,16] The respondents with personal history of hypertension were excluded from the study since they have known preexisting hypertension which is the foundation of cardiovascular diseases. Diabetes mellitus was defined based on the presence of personal history of diabetes mellitus and/or patient was on anti-diabetic medications or for patients without personal history of diabetes mellitus, fasting venous plasma glucose of $\geq 126 \mathrm{mg} / \mathrm{dL}$ which was confirmed by a repeat test on second clinic visit.

\subsection{Methods}

Data collection instrument had two sections: clinical data collection schedule section which contained information on clinical parameters such as blood pressure measurement, blood glucose estimation and body mass index; and questionnaire section on basic demographic and behavioural variables. The questionnaire instrument was adapted from the generic WHO-STEPS instrument approach to surveillance of chronic non-communicable diseases risk factors [29] and was modified to suit Nigeria environment through robust review of relevant literature.[6,12,13,17,21,22,28] The demographic variables collected from the study population included age, sex, marital status, education, occupation, social class and family history of CVDs . The social classification of patients was divided into lower, middle and upper occupational classes to suit Nigerian environment.[6]

The family history of CVD was coded as yes or no for the presence or absence of CVDs such as hypertension, heart failure, myocardial infarction or stroke in any of the first, second or third degree generation family members respectively. The researchers explained briefly the concept of the study and made vigorous effort to maximize positive response in order to minimize the potential for information bias especially response acquiescence and social desirability response.

The behavioural risk factors evaluated were physical activity, alcohol consumption and tobacco use. Alcohol consumption was assessed in the previous 12 months preceding the study and coded yes or no for someone who used less than a unit or a unit of any type of alcohol daily or occasionally in 12 months preceding the study or someone who had never used alcohol in the previous 12 months preceding the study respectively. A unit of alcohol is equivalent to $10 \mathrm{~g}$ of alcohol. Similarly, tobacco use was evaluated with respect to the use of smoked and smokeless tobacco in the lifetime and coded yes or no for someone who had used smoked or smokeless tobacco in any form either daily or occasionally in their lifetime or someone who had never used tobacco in their lifetime respectively. Physical activity was categorized as active or inactive. Those engaged in activities that cause a moderate or large increase in breathing or heart rate are considered physically active while the level of activity below this was considered physical inactivity. The physical activities were assessed in the previous 30 days. Subject's occupational and activities of daily living were taken into consideration in assessing for the physical activity profile.

The pre-testing of the questionnaire was done internally at the primary care clinic of the hospital using ten patients without family history of CVD. The pre-testing of the questionnaire lasted for two days. The respondents for the pre-testing of the questionnaire were selected haphazardly from the clinic. The pretesting was done to find out how the questionnaire would interact with the respondents and ensured that there were no ambiguities. However, no change was necessary after the pre-test as the questions were interpreted with the same meaning as intended.

The questionnaire instrument was intervieweradministered. Language used was English Language. However, local languages were used to explain verbally to the patients who could not understand the medical language in the questionnaire. The questionnaire was administered by the corresponding author and three resident doctors who were trained and recruited for the study. The questionnaire was administered once to each eligible respondent.

\subsection{Operational Definitions}

Cardiovascular disease(CVD) is the umbrella name for a group of diseases of the heart and vascular system. The major non-communicable CVDs include hypertension, heart failure, ischaemic heart disease and stroke. Risk factors of non-communicable CVD refers to antecedent condition(s) whose presence is(are) positively associated with an increased probability that CVD will develop later. The risk factors studied included the traditional nonmodifiable factors of age, sex, family history of CVD; modifiable cardio-metabolic risk factors of hypertension, obesity, dyslipidaemia and diabetes and behavioural risk factors of physical inactivity, excessive alcohol use and tobacco use.

Family history of CVD refers to previous information on any major non-communicable CVDs such as hypertension, heart failure, myocardial infarction or stroke in any of the first, second or third degree generation family members who were dead or alive made by a health professional. Primary care refers to the care provided by physicians specifically trained for comprehensive first contact and continuing care for undifferentiated patients including early detection, management of the patient, health promotion and 
maintenance. Artisans refer to manual workers and include masons (bricklayers), fitter mechanics, electricians, tailors, seamstresses, hair dressers and carpenters.

\subsection{Statistics}

The results generated were analyzed using software Statistical Package for Social Sciences (SPSS) version 13.0, Microsoft Coperation Inc. Chicago, IL, USA for the calculation of percentages for categorical variables and mean for continuous data.

\section{Results}

Four hundred and forty patients were studied. The age of these patients ranged from 18 years to 76 years with a mean age of $43 \pm 7.1$ years. There were $194(44.1 \%)$ males and 246 (55.9) females with male to female ratio of 1: 1.3. Other demographic profiles of the study population are shown in table 1 .

Table 1: Basic demographic profile of the study population

\begin{tabular}{|c|c|}
\hline Parameter & Number(\%) \\
\hline \multicolumn{2}{|l|}{ Age(years) } \\
\hline $18-39$ & $175(39.8)$ \\
\hline $40-60$ & $207(47.1)$ \\
\hline$>60$ & $58(13.1)$ \\
\hline Total & $440(100.0)$ \\
\hline \multicolumn{2}{|l|}{ Sex } \\
\hline Male & 194(44.1) \\
\hline Female & $246(55.9)$ \\
\hline Total & $440(100.0)$ \\
\hline \multicolumn{2}{|l|}{ Marital status } \\
\hline Single & $105(23.9)$ \\
\hline Married & 281(63.9) \\
\hline Widowed & $39(8.8)$ \\
\hline Separated/divorced & $15(3.4)$ \\
\hline Total & $440(100.0)$ \\
\hline \multicolumn{2}{|l|}{ Education } \\
\hline Primary and less & $71(16.1)$ \\
\hline Secondary and more & $369(83.9)$ \\
\hline Total & $440(100.0)$ \\
\hline \multicolumn{2}{|l|}{ Occupation } \\
\hline Unemployed & $31(7.0)$ \\
\hline Student/apprentice & $37(8.4)$ \\
\hline Public/civil servants & $199(45.2)$ \\
\hline Farming & $46(10.5)$ \\
\hline Trading & $56(12.7)$ \\
\hline Driving & 17(3.9) \\
\hline Artisans & $21(4.8)$ \\
\hline Clergy & $4(0.9)$ \\
\hline $\begin{array}{l}\text { Retired public/civil servants with no } \\
\text { secondary occupation }\end{array}$ & $19(4.3)$ \\
\hline $\begin{array}{l}\text { Retired public/civil servants and } \\
\text { engaged in secondary occupation }\end{array}$ & $10(2.3)$ \\
\hline Total & $440(100.0)$ \\
\hline \multicolumn{2}{|l|}{ Social class } \\
\hline Lower & $147(33.4)$ \\
\hline Middle & $237(53.9)$ \\
\hline Upper & $56(12.7)$ \\
\hline Total & $440(100.0)$ \\
\hline
\end{tabular}

Table 2: Distribution of cardio-metabolic and behavioural risk factors of the study population

\begin{tabular}{|c|c|c|}
\hline Variables & Number & Percentage \\
\hline \multicolumn{3}{|c|}{ Hypertension } \\
\hline Yes & 116 & 26.4 \\
\hline No & 324 & 73.6 \\
\hline Total & 440 & 100.0 \\
\hline \multicolumn{3}{|c|}{ Obesity(Body Mass Index) } \\
\hline$\geq 30$ & 83 & 18.9 \\
\hline$<30$ & 357 & 81.1 \\
\hline Total & 440 & 100.0 \\
\hline \multicolumn{3}{|c|}{ Diabetes mellitus } \\
\hline Yes & 34 & 7.7 \\
\hline No & 406 & 92.3 \\
\hline Total & 440 & 100.0 \\
\hline \multicolumn{3}{|c|}{ Physical activity status } \\
\hline Active & 81 & 18.4 \\
\hline Inactive & 359 & 81.6 \\
\hline Total & 440 & 100.0 \\
\hline \multicolumn{3}{|c|}{ Alcohol use } \\
\hline Yes & 77 & 17.5 \\
\hline No & 363 & 82.5 \\
\hline Total & 440 & 100.0 \\
\hline \multicolumn{3}{|c|}{ Tobacco use } \\
\hline Yes & 25 & 5.7 \\
\hline No & 415 & 94.3 \\
\hline Total & 440 & 100.0 \\
\hline
\end{tabular}

The three most frequent cardiovascular risk factors were physical inactivity $(81.6 \%)$, asymptomatic hypertension $(26.4 \%)$ and obesity (18.9\%). Others included alcohol use $(17.5 \%)$, diabetes mellitus $(7.7 \%)$ and tobacco use $(5.7 \%) .[$ Table 2]

\section{Discussion}

Physical inactivity $(81.6 \%)$ is the most common cardiovascular risk factors among the study population. The detrimental impact of physical inactivity has been documented in relationship to chronic medical conditions.[30,31] Available evidence has shown that physical inactivity is an important contributor to cardiovascular diseases and lack of involvement in physical activity may predispose to cardiovascular health problems.[31-33] Physical activity is therefore not an activity that anybody outgrows because of its beneficial effects in preventing primary and secondary adverse cardiac events.[32,34-36] Apart from the metabolic homeostasis associated with physical activity, physical activity has been reported to reduce cardiovascular risk through reduction of blood pressure, improve glucose tolerance, lipid profile and endothelial function, enhanced 
fibrinolysis and parasympathetic autonomic tone and through other yet undetermined mechanisms.[30,35,36] Clinicians should therefore explain to their patients with family history of cardiovascular diseases in sufficient details the health implications of physical inactivity. The physical activity primary prevention intervention strategies for cardiovascular diseases have best benefit-to-risk and benefit-to-case ratios of any pharmaceutical therapeutic interventions for cardiovascular diseases. This information should not only be limited to the consequences of physical inactivity but also the benefits of physical activity in the overall cardiovascular health and diverse medical conditions.

Asymptomatic hypertension was the second most common CV risk factor among the study population. The frequency of asymptomatic hypertension of $26.4 \%$ in this study is within the hypertension prevalence range of $8.0 \%$ $46.4 \%$ reported in a systematic review of prevalence of hypertension in adult Nigerian Africans [7] and 22.5\% $31.0 \%$ reported in adult Nigerians in Abia state noncommunicable disease study. [37] However, the prevalence of asymptomatic hypertension in this study was skewed towards the upper limits of the reported hypertensive prevalence range in the non-communicable disease study in Abia State, Nigeria where the Federal Medical Centre, Umuahia is located. The asymptomatic nature of hypertension, [11,38] family history of hypertension, poor awareness of the relevance of hypertension in Nigeria[11,39] and poor blood pressure detection rates in Nigeria [40] could have contributed to this prevalence. The finding of this study has buttressed the reports that hypertension is one of the principal risk factors for cardiovascular diseases and foundation of epidemic of CVDs due to its role in the causation cardiovascular complications.[41-43] According to these reports, hypertension is a gateway to non-communicable CVDs $[41,42]$ and poses clinical and public health challenge particularly in nations in socio-economic, demographic and epidemiological transition. Studies have demonstrated that most human hypertension develops from interaction of multiple genes, socio-behavioural and environmental factors among others.[44-46] Family history of CVDs is therefore a reflection of not only genetic predisposition but also susceptibility and interactions between genetic and behavio-environmental factors. Due to this constitutional genetic predisposition and clustering of hypertension in families, the family history of any of the cardiovascular diseases should therefore inform the need to evaluate for hypertension and other cardiovascular diseases in order to identify covert and overt cases requiring treatment and control. Early detection of hypertension in individuals with family history of CVD is quintessential in cardiovascular risk factor management since it has been documented that as the number of $\mathrm{CV}$ risk factors increases so does the occurrence of CVDs increases.[1-5,16,28] The earlier the primary prevention is started the more likely it is to be effective. Clinicians should therefore be aware of these subtleties and endeavour to detect early the addition of hypertension on patients with family history of CVD during clinical encounter in primary care setting.

Obesity was the third most common cardiovascular risk factors among the study population. The prevalence of obesity of $18.9 \%$ in this study is within the $8.1 \%-22.2 \%$ reported in a systematic review of prevalence of obesity in adult Nigerians but the prevalence value in this study was skewed to the upper prevalence range.[47] This study has therefore buttressed the reports of the growing evidence of obesity epidemics in Nigeria.[6,47,48] The finding of this study is very important especially in Nigerian sociocultural environment where body build at the level of obesity is not always perceived as a health risk. [6,49,50] The local perception of obesity as a feature of affluence and good living is common. [6,49,50] Human obesity has been considered to be the direct result of chronic ingestion of excess calories and physical inactivity, but there is strong evidence of genetic influence. [6,49-51] Although fats act as storage organ for excess calories, its generalized distribution is however associated with increased risk of cardiovascular diseases and impacts negatively on the quality of life. [6,48-50] Obesity can therefore have adverse effects on the physical health of these patients and can trigger other acute and chronic complications of obesity. [48] The addition of obese risk factor in patients with family history of cardiovascular diseases needs further attention in primary care setting in resource-constrained environment. Screening patients with family history of cardiovascular diseases for obesity needs to be at initial clinical encounter as the development and damage by obesity start even before the diagnosis is made. The longitudinal and latitudinal care of these patients should be a primary care challenge especially in resource-constrained setting where there are limited options for healthy living.[25,26,51]

\section{Implications of the Study}

Cardiovascular diseases have been implicated for rising morbidity and mortality from non-communicable diseases in Nigeria and carry great concern for the future.[6,7,10,1113] Cardiovascular diseases are therefore important primary care health problem and one of the leading causes of premature deaths in the affected families.[10] Although there are many constraints to the control of cardiovascular diseases in Nigeria, appropriate intervention measures are urgently needed to prevent the burden of cardiovascular diseases and this requires data on cardiovascular risk factors particularly for the vulnerable group such as those with family history of cardiovascular disease.

Cardiovascular risk factors tend to cluster in persons with family history of cardiovascular diseases and this informed the need to sensitize clinicians to screen these high risk patients for cardio-metabolic risk factors and assess them for behavioural risk factors during clinical encounter in primary care settings. Consequently, primary 
prevention of cardiovascular diseases should focus on screening for family history of cardiovascular diseases in addition to other CV risk factors as well as strategic control measures as part of bio-socio-environmental risk factor evaluation. This study therefore informs the need for primary care facility based screening for $\mathrm{CV}$ risk factors as part of bio-socio-environmental risk factor assessment in persons with family history of cardiovascular disease for preliminary determination of the need for lifestyle modification that will help to establish a culture of healthy living.

\section{Limitations of the Study}

The authors had certain constraints which imposed some degree of limitations to the absolute generalization of the findings: First and foremost, the sample was drawn from hospital attendees in the study area as only patients who presented to the clinic were studied. Thus extrapolation and generalization of the results of the study to the entire population in the study area should be done with utmost caution because the findings may not be a true representation of what may be obtained in the community.

Moreover, this study was not an all inclusive study on conventional and novel cardiovascular risk factors but on some selected traditional risk factors such as hypertension, obesity, diabetes mellitus, physical activity, alcohol and tobacco use. More so, although waist indices such as waist circumference which is a measure of central obesity has been reported to be more patho-genetically important in the aetiology of cardio-metabolic disorder but body mass index which is a measure of generalized obesity has high correlation with body fat, and is the most popular index for estimating body fat in individual subjects that can be compared across studies and populations and is therefore considered at least as important a medical risk as abdominal obesity.

In addition, this study was dependent on self-reported behavioural factors and family history of cardiovascular disease in the first, second and third degree relatives. However, some respondents were either reluctant to give correct information regarding family history of cardiovascular disease. Some respondents were not sure whether their relatives were afflicted by cardiovascular disease or not. This could have led to response acquiescence, social desirable response and recall bias. In order to minimize recall biases the questions were structured in a manner that will enable the researcher obtain information relevant to the objectives of the study. This objectivity was also maintained by not fielding misleading questions. The researchers ensured that questions were not ambiguous or presented to the respondents in such a way as to communicate different meanings that could generate inaccurate and inconsistent responses.

Furthermore, the assessment for the behavioural risk factors of alcohol and tobacco use was not quantitative as regards the cardiovascular relevance of occasional or rarely use of alcohol or tobacco which may not predispose to cardiovascular disease as to reduce the incidence of cardiovascular disease.

\section{Conclusion}

This study has shown the frequency of CV risk factors among the study population with three most common being physical inactivity, asymptomatic hypertension and obesity. Screening adult Nigerians with family history of CVD for cardio-metabolic and behavioural CV risk factors should form baseline evaluation during consultation in primary care. More so, early interventions to prevent CVD in these at risk persons with family history of CVD should be a compelling health priority in primary care settings particularly in resource-constrained environment.

\section{References}

[1] Yach D, Hawkees C, Gouuld CL, Hofman KJ. The global burden of chronic diseases: overcoming the impediments to prevention and control. JAMA 2004; 291: 2616-2622.

[2] Lawoyin TO, Asuzu MC, Kaufman J, Rotimi C, Owoaje E, Johnson L, Cooper R. Prevalence of cardiovascular factors in an African urban inner city community. West Afr J Med 2002; 21: 208-211.

[3] Kadiri S. Tackling cardiovascular diseases in Africa. BMJ, West Africa edition 2005;8: 172-173.

[4] Gaziano TA, Gaziano JM. Epidemiology of cardiovascular diseases. In Fauci AS, Braunwald E, Kasper DL, Hauser SI, Longo DL, Jameson JL and Loscalzo J editors. Harrison's Principles of Internal Medicine, $17^{\text {th }}$ edn. New York, McGraw Hill Medical 2008: p. 1375-1379.

[5] Gaziano JM. Global burden of cardiovascular disease. In Braunwald Heart disease: A Textbook of cardiovascular Medicine, $8^{\text {th }}$ edn. Philadelphia, Elservier Saunders 2008: p. 3-20.

[6] Iloh GP, Ikwudinma AO, Obiegbu NP. Obesity and its cardio-metabolic co-morbidities among adult Nigerians in a primary care clinic of a tertiary hospital in South-Eastern Nigeria. J Fam Med Primary Care 2013; 2: 20-26

[7] Ogah OS, Okpechi I, Chukwuonye II, Akinyemi JO, Onwubere BJC, Falase AO, Stewart S, Sliwa K. Blood pressure, prevalence of hypertension and hypertension related complications in Nigerian Africans: A review. World J Cardiol 2012; 4: 327-340.

[8] Pandve HT, Chawla PS, Fernandez K. Recent developments in cardiovascular diseases control and prevention in India. $\mathrm{J}$ Fam Med Primary Care 2012; 1: 79-80.

[9] Al-Baghli NA, AL-Ghamdi AJ, Al-Turki KA, El-Zubaier AG, Al-Mostafa BA, Al-Baghli FA, Al-Ameer MM. Awareness of cardiovascular disease in eastern Saudi Arabia. J Fam Community Med 2010; 17: 15-21.

[10] Arodiwe EB, Ike SO, Nwokediuko SC. Case fatality among hypertension-related admissions in Enugu, Nigeria. Niger J Clin Pract 2009; 12: 153-156. 
[11] Akinkugbe OO. Non-communicable diseases in Nigeria. The next epidemics; Abayomi Memorial Lectures. Niger J Med Pract 2000; 3: 904-907.

[12] Oghagbon EK, Okesina AB. Pattern of some risk factors for cardiovascular disease in untreated Nigerian hypertensive patients. West Afr J Med 2006; 25: 190-194.

[13] Akindele MO, Uba M. Incidence and Pattern of Cardiovascular Disease in North Western Nigeria. Niger Med J 2009; 50: 55-57.

[14] Kengne AP, Awah PK, Fezeu L, Mbanya JC. The burden of high blood pressure and related risk factors in urban subSaharan Africa: Evidences from Douala in Cameroon. Afr Health Sci 2007; 7: 38-44.

[15] Yusuf S, Reddy S, Ounpuu S, Anand S. Global burden of cardiovascular diseases: Part II: variations in cardiovascular disease by specific ethnic groups and geographic regions and prevention strategies. Circulation 2001; 104: 2855-2864.

[16] Chobanian AV, Bakris GL, Black HR, Cushman WC, Green LA, Izzo JL et al. The seventh report of the Joint National Committee on Prevention, Detection, Evaluation and Treatment of high blood pressure: The JNC VII report. JAMA 2003; 289: 2560- 2572.

[17] Sani MU, Wahab KW, Yusuf BO, Gbadamosi M, Johnson OV, Gbadamosi A. Modifiable cardiovascular risk factors among apparently healthy adult Nigerian population-a cross sectional study. BMC Res Notes 2010; 3:11.

[18] Keddy KS. Cardiovascular diseases in the developing countries: dimensions, determinants, dynamics and direction for public health action. Public Health Nutr 2002; 5: 231237.

[19] Magnus P, Beaglehole R. The real contribution of the major risk factors to the coronary epidemics: Time to end the “'Only 50\%”' Myth. Arch Intern Med 2001; 161: 2657-2660.

[20] Rich EC, Burke W, Henton CJ, Haga S, Pinsky L, Short P, et al. Reconsidering the family history in primary care. J Gen Intern Med 2004; 19: 273-280.

[21] Ike SO, Arodiwe EB, Onoka CA. Profile of Cardiovascular Risk Factors among Priests in a Nigerian Rural Community. Niger Med J 2007; 48: 79-84.

[22] Nwachukwu L, Inem V, Ajuluchukwu JNA, Ayankogbe OO, Jarikre A. Cardiovascular Risk Factors in Nigerian Company Executives Presenting for Group Life Assurance Policy. Niger Hospital Pract 2007; 1: 13-16.

[23] Yoon PW, Scheuner MT, Peterson-oehlke KL, Gwinn M, Faucett A, Khoury MJ. Can family history be used as a tool for public health and preventive medicine? Genet Med 2002; 4: 304-310.

[24] Keddy KS, Katan MB. Diet, Nutrition and the prevention of hypertension and cardiovascular diseases. Public Health Nutr 2004; 7(1A): 167-186.

[25] World Health Organization. Preventing chronic diseases: a vital investment. Geneva. World Health Organization 2005.

[26] Dominguez LJ, Galioto A, Ferlisi A, Pineo A, Putignario E, Belvedera M. Aging, lifestyle modifications and cardiovascular disease in developing countries. J Nutr Health Aging 2006; 10: 143- 9.
[27] Araoye MO. Sample size determination. Research Methodology with Statistics for Health and Social Sciences, Ilorin, Nathadex Publishers, 2004; p.115-121.

[28] Onwubere B, Kadiri S. Guidelines for the management of hypertension in Nigeria. Nigerian Hypertension Society. Enugu, Ezu Books Limited 2005.p. 1-40

[29] WHO. Survey of the STEPwise approach for the survellaince of risk factors for non-communicable diseases, Brazzaville, WHO, Region office for Africa, 2007.

[30] Myers J. Exercise and Cardiovascular Health. Circulation 2003; 107: 2 .

[31] Lee IM. Effect of physical inactivity on major noncommunicable diseases worldwide: an analysis of burden of disease and life expectancy. Lancet 2012; 380: 219-229.

[32] Wessel TR, Arant CB, Olson MB, Johnson BD, Reis SE, Sharaf BL, et al. Relationship of physical fitness vs body mass index with coronary artery disease and cardiovascular events in women. JAMA 2004; 292: 1179-1187.

[33] Sobngwi E, Mbanya JC, Unwin NC. Physical activity and its relationship with obesity, hypertension and diabetes in urban and rural Cameroon. Int J Obes.Relat Metab Disord 2003; 26: 1009-1016.

[34] WHO. Global strategy on diet, physical activity and health. Bulletins of the WHO 2006; 5: 16-18.

[35] Warburton DER, Nicol CW, Bredin SSD. Health benefits of physical exercise: the evidence. CMAJ 2006; 174: 801-809.

[36] Adamu B, Sani MU, Abdu A. Physical Exercise and Health: A Review. Niger J Med 2006; 15: 190-196.

[37] Ogah OS, Madukwe OO, Chukwuonye II, Onyeonoro UU, Ukaegbu AU, Akhimien MO et al. Prevalence and determinants of hypertension in Abia State Nigeria: results from the Abia State Non-Communicable Diseases and Cardiovascular Risk Factors Survey. Ethn Dis 2013; 23: 161-167.

[38] Oke DA, Bandele EO. Misconception of hypertension. J Natl Med Assoc 2004; 96: 1221-1224.

[39] Omuemu VO, Okojie OH, Omuemu CE. Awareness of high blood pressure status, treatment and control in a rural community in Edo state. Niger J Clin Pract 2007; 10:208212.

[40] Iloh GUP, Ofoedu JN, Njoku PU, Amadi AN, Godswill-Uko EU. Medication adherence and blood pressure control amongst adults with primary hypertension attending a tertiary hospital primary care clinic in Eastern Nigeria. African Journal of Primary Health Care \& Family Medicine 2013 ;5: 446.

[41] Cooper RS, Amoah AG, Mensah GA. High blood pressure: the foundation for epidemic cardiovascular diseases in African population. Ethn Dis 2003; 13(2 Suppl 2): S48-52

[42] Bhatt DL, Steg PG, Ohman EM. International prevalence, recognition and treatment of cardiovascular risk factors in outpatients with atherothrombosis. JAMA 2006; 295: 180189.

[43] Iloh GUP, Amadi AN, Chuku A. Burden of noncommunicable diseases among geriatric Nigerians in a rural hospital in resource-constrained setting of Eastern Nigeria. 
Science Journal of Public Health 2013; 1: 141-146.

[44] Caulfield M, Munroe P, Pembroke J, Samani N, Dominiczak A, Brown M, et al. Genome-wide mapping of human loci for essential hypertension. Lancet 2003; 361: 2118-2123.

[45] Yoon PW, Scheuner MT, Khoury MJ. Research priorities for evaluating family history in the prevention of common chronic diseases. Am J Prev Med 2003; 24:128-135.

[46] Goldstein IB, Shapiro D, Guthrie D. Ambulatory blood pressure and family history of hypertension in healthy men and women. Am J Hypertens 2006; 19: 486-491.

[47] Chukwuonye II, Chuku A, John C, Ohagwu KA, Imoh ME, Isa SE, Ogah OS, Oviasu E. Prevalence of overweight and obesity in adult Nigerians-a systematic review. Diabetes Metabolic Syndrome and Obesity: Targets and Therapy 2013; 6: 43-47.
[48] Ogunbode AM, Ladipo M, Ajayi IO, Fatiregun AA. Obesity: A emerging disease. Niger J Clin Pract 2011; 14: 390-394.

[49] Iloh GUP, Amadi AN, Nwankwo BO. Obesity in adult Nigerians: a study of its prevalence and common primary co-morbidities in a semi-urban Mission General Hospital in South-Eastern Nigeria. Niger J Med 2010; 19: 459-466.

[50] Iloh GUP, Amadi AN, Nwankwo BO, Ugwu VC. Obesity in adult Nigerians: A study of its pattern and common primary co-morbidities in a rural Mission General Hospital in Imo state, south-eastern Nigeria. Niger J Clin Pract 2011; 14: 212-218.

[51] Oyekan AO. Genetics of Food Intake, Body Weight and Obesity-Role of Leptin. Niger Med Pract 2005; 47: 108-112.

[52] WHO. Innovative care for chronic conditions: building blocks for action. Geneva: World Health Organization, 2002. 